\title{
A Relação entre Austeridade Fiscal e Bem Social nos Municípios Brasileiros
}

\author{
Eugenio dos Santos Miranda ${ }^{1}$; Deise Cristiane do Nascimento ${ }^{2}$
}

Resumo: Esse estudo configura-se como um levantamento de dados como intuito de refletir sobre a função política e social dos Estados e Municípios, demarcando pontos como o endividamento no setor público e o bem-estar social da população. O levantamento de informações foi realizado em junho de 2015 , na base de dados encontrados em órgãos oficiais do Governo em suas três instancias, federal, estadual e municipal. As variáveis estudadas nesse trabalho são: Lei de Responsabilidade Fiscal e bem-estar social, e o instante temporal entre 1991 a 2015. Dentre os Municípios do Sub Médio São Francisco serão estudados, Juazeiro e Remanso na Bahia; e Petrolina e Ouricuri, em Pernambuco foram incluídos nessa pesquisa por serem municípios em destaque pelo crescimento econômico e por localizarem-se no Sub Médio São Francisco.

Palavras-chave: Bem-estar social; Lei de responsabilidade fiscal; Municípios; Sub Médio São Francisco.

\section{The Relationship between Fiscal Austerity and Social Wellness in Brazilian Municipalities}

\begin{abstract}
This study is configured as a survey data as order to reflect on the political and social role of states and municipalities, marking points as debt in the public sector and the welfare of the population. The survey information was held in June 2015, the database found in Government official bodies in its three instances, federal, state and municipal.The variables studied in this work are: the Fiscal Responsibility Law and social well-being, and timestep from 1991 to 2015. Among the municipalities of Sub Middle São Francisco will be studied, and Juazeiro and Remanso in Bahia; and Petrolina and Ouricuri, Pernambuco were included in this study because they are municipalities highlighted by economic growth and are located in Sub-middle São Francisco.
\end{abstract}

Keywords: Social Welfare; Fiscal responsibility law; municipalities; Sub Middle São Francisco.

\section{Introdução}

O segmento social possui recursos escassos e grande necessidade de investimento. Dito de outra forma, as receitas não são suficientes para cobrir os gastos e despesas dos órgãos públicos, a fim de satisfazer as necessidades da coletividade, gerando assim um déficit orçamentário na administração pública. Para cobrir esse déficit os gestores públicos acabam por buscar recursos financeiros através de empréstimos isso faz que, com a passagem do tempo, o município contraia dívidas enormes, deixando-as de herança para gestões posteriores, o que gera uma crescente dívida.

\footnotetext{
${ }^{1}$ Possui graduação em Ciências Contábeis pela Faculdade de Ciências Aplicadas e Sociais de Petrolina (2009). Atualmente é contador da Prefeitura Municipal de Afranio e professor bolsista do Instituto Federal de Pernambuco.

${ }^{2}$ Especialização em Gestão em Administração Pública pela Universidade Castelo Branco. Bolsista CNPQ da Universidade Federal do Vale do São Francisco - UNIVASF, Brasil. Autor correspondente. E-mail: deise.nascimento@fecape.br.
} 
Com intuito de controlar e amenizar o endividamento dos municípios surgiu a Lei de Responsabilidade Fiscal, Lei que determina limites de gastos e endividamento do poder público e a diversos outros aspectos das finanças públicas, impondo assim que a dívida consolidada líquida deve ser diminuída gradativamente com acompanhamento bimestral dessas por órgãos fiscalizadores através dos chamados Resultados Nominais. Caso esses resultados não tenham sido alcançados, os municípios são penalizados com sanções como corte de verbas para programas sociais.

Partindo dessa perspectiva, este trabalho tem como objetivo principal relatar sobre a Austeridade Fiscal nos municípios de Juazeiro, Remanso na Bahia; e Petrolina e Ouricuri no Pernambuco, situados no Sub Médio São Francisco, e sua relação com o bem-estar social, identificando como a população desses municípios estão sendo beneficiadas com a criação da Lei de Responsabilidade Fiscal. Assim, busca-se responder a seguinte problemática: quais os efeitos decorrentes da aplicação da Lei de Responsabilidade Fiscal nos municípios pesquisados e de que forma ela tem contribuído para que haja uma melhor aplicação dos recursos?

Para consecução dos objetivos almejados, essa pesquisa, de cunho descritivo buscou descrever, a partir de pesquisa de levantamento bibliográfico em sites oficiais do Governo Federal, de que forma a instituição da referida Lei tem impactado positivamente os pesquisados.

\section{Metodologia}

O presente trabalho caracteriza-se como um estudo descritivo. A pesquisa descritiva tem como objetivo primordial a descrição de características de um determinado fenômeno e ou população e ou o estabelecimento de relações entre variáveis. (GIL, 2008). Assim, no caso desse trabalho buscou-se descrever os efeitos da austeridade fiscal nos municípios do Sub Médio São Francisco: Juazeiro e Remanso na Bahia; e Petrolina e Ouricuri, em Pernambuco. Desse modo, questionando os efeitos da Gestão Fiscal sobre o bem-estar dos indivíduos e descrevendo as características mais marcantes do fenômeno da austeridade fiscal.

A escolha dos municípios supracitados se deu pelo fato de esses municípios serem destaque no que se refere ao crescimento econômico e também por serem localizados no Sub Médio São Francisco. Vale destacar que as variáveis estudadas nesse trabalho foram austeridade fiscal e bem-estar social, e o instante temporal entre 1991 a 2015.

Para a realização desse estudo, foi usado como instrumento de pesquisa o levantamento de dados bibliográficos, tendo como fonte de dados documentos de base secundários. O levantamento de informações foi realizado em junho de 2015, em sites oficiais do governo brasileiro. Para dar início a 
coleta de dados em sites oficiais, foi feita a busca através do nome de cada município aqui estudado, prioritariamente foi dado atenção aos relatórios de cada município.

Vale ressaltar que, mesmo sendo embasado por dados quantitativos foi dada a esta pesquisa o enfoque qualitativo aos dados levantados, isso porque para que a pesquisa tivesse mais relevância foi necessária a ampliação das visões e conceitos do fenômeno estudado. Para Bardim (1977, 42), a análise qualitativa:

Designa um conjunto de técnicas de análise das comunicações visando a obter, por procedimentos sistemáticos e objetivos de descrição do conteúdo das mensagens, indicadores (quantitativos ou não) que permitam a inferência de conhecimentos relativos às condições de produção/recepção (variáveis inferidas) destas mensagens.

\section{Referencial Teórico}

\section{Gestão Pública}

É importante entender a conceituação de administração pública, para que posteriormente seja possível compreender aspectos do controle orçamentário e da austeridade fiscal. A constituição Federal de 1988 trouxe um capitulo inteiro dedicado à caracterização da administração pública. Segundo Serpa (2005 p. 15):

(...) a ideia de administração pública compreende desempenho dos serviços de utilidade pública ou de interesse coletivo realizado pelo Estado. Cabe a Administração Pública cumprir os fins esperados e expressos pela ordem jurídica, sendo para isso regida pelos princípios trazidos pela $\mathrm{CF} / 88$.

No art. 37 da Constituição Federal de 1988, são explicitados os princípios que a Administração Pública deve obedecer, são eles os princípios da legalidade, impessoalidade, moralidade, publicidade e eficiência. Para Serpa (2005) esses princípios formam a base e fundamentam as ações da Administração Pública. Sobre isso, Ribeiro Filho (1997, p. 12) afirma que:

\footnotetext{
A Administração Pública compreende os meios de que se serve o Estado, entendido como ente soberano, organizado sobre um território para fins de defesa, bem-estar, ordem e progresso social, para efetivar o atendimento das necessidades públicas. Todo o conjunto da estrutura patrimonial de bens, equipamentos, tecnologias e servidores públicos, distribuídos sistematicamente em funções, programas, projetos e atividades, submetidos à lógica da captação e aplicação de recursos e organizados sob a égide da legalidade, impessoalidade, moralidade e publicidade dos atos, traduz a macro - entidade denominada de Administração Pública.
} 
Ribeiro Filho, na citação supracitada, permite entender a Administração Pública de maneira mais prática, como a instrumentalização do estado para cumprir seu papel diante da sociedade, especificando ainda os princípios que regem a administração pública e que permitem que as atividades/trabalhos realizadas possam ser desenvolvidas de modo ético respeitando a constituição e o cidadão.

Pode-se afirmar que a administração pública é todo o sistema que administra o Estado, que visa atender a demanda da sociedade de modo responsável e sustentável. É importante ressaltar que a administração pública é a via de promoção do direito público. Para complementar a conceituação de administração pública tem-se:

Com a implementação do Plano Diretor da Reforma do Aparelho do Estado em 1995 está sendo adotado o seguinte conceito para a administração pública: "é todo o aparelho do Estado préorientado à realização de seus serviços, visando à satisfação das necessidades coletivas" (MINISTÉRIO PÚBLICO, 2001).

Neste contexto é notório que a meta maior de todo administrador público deve ser a de prestar serviço à sociedade de modo que possa dar conta das necessidades coletivas.

\section{Bem-estar Social}

Garantir o bem-estar Social é dever do Estado. Gontijo e Araujo (2006) convergem para essa ideia ao afirmar que:

É função do Estado, atender às necessidades da coletividade, de forma a garantir o bem-estar social. Para isso, é necessário que os recursos sejam alocados adequadamente. É imprescindível, portanto, a existência de ações planejadas para que os recursos públicos sejam destinados com eficiência e equidade, pois os gastos desordenados promovem desequilíbrio nas finanças públicas, resultando em endividamento, o que inviabiliza a implementação de políticas públicas que atendam às reais necessidades da sociedade.

Para que o Estado possa atender as reais necessidades da sociedade, é preciso que as arrecadações sejam melhores aplicadas. Nesse contexto, para auxiliar no controle o orçamento público foi criada a Lei de Responsabilidade Fiscal que para Alves opud Gontijo e Araujo (2006):

A LRF pretende fortalecer o orçamento anual fazendo com que ele seja, efetivamente, um plano, prevenindo-se, assim, desequilíbrios fiscais inesperados, dando um efetivo rumo para os entes federativos, por meio de uma programação condizente com a realidade. A idéia é fazer com que o administrador público se comprometa em gerir com competência e planejamento os recursos para o bem-estar da sociedade. 
Entretanto, a LRF possibilita maior controle sobre os gastos públicos, para que assim possa diminuir e até impedir o desequilíbrio fiscal. Para isso define limites e metas que devem ser alcançadas pelos municípios, como também define sanções para os municípios que descumprirem os critérios estabelecidos. O próximo tópico traz maior detalhamento sobre a LRF.

\section{A Lei de Responsabilidade Fiscal}

Para ofertar os serviços demandados pela sociedade no que se refere à saúde, educação, infraestrutura, dentre outros aspectos, é preciso que haja receita financeira de modo que a Administração Pública necessita gerenciar de forma sustentável seu orçamento, de modo que seus gastos não sejam maiores que a arrecadação. Para que seja possível, o equilíbrio orçamentário, foi criado a Lei de Responsabilidade Fiscal.

Desse modo é pertinente entender o que é a Lei de Responsabilidade Fiscal e qual sua funcionalidade, a LRF, também chamada de lei complementar $n^{\circ} 101$ de Maio de 2000, configura-se como o principal instrumento regulador dos gastos públicos, e para isso estabelece metas, limites e condições para gestão das receitas e das despesas públicas. Segundo Claudiano (2011) a lei complementar dispõe sobre:

I-finanças públicas; II-dívidas públicas externas e internas, incluída a das autarquias, fundações e demais entidades controladas pelo poder público; III-concessão de garantias pelas entidades controladoras pelo poder público; IV-emissão e resgate de títulos da divida pública; V-fiscalização das instituições financeiras; VI-operações de cambio realizadas por órgãos e entidades da união, dos estados, do Distrito Federal e dos Municípios; VII-compatibilização das funções das instituições oficiais de crédito da União resguardadas as características e condições operacionais plenas das voltadas ao desenvolvimento regional;

A Lei de Responsabilidade Fiscal foi sancionada em maio de 2000, e foi elaborada com a finalidade de atender as expectativas da sociedade brasileira, no que se refere à responsabilidade e ao bom uso dos recursos públicos.

Isso permite que se possa entender que a Lei de Responsabilidade Fiscal engloba tudo que diz respeito e que se relaciona com a organização financeira e orçamentária pública, indo desde a regulamentação e regulação de instituições financeiras, operações de finanças e crédito até a compatibilização das funções.

A transparência e responsabilidade são pilares básicos da LRF. Como todo modelo eficiente, a lei se baseia em um princípio simples e exige apenas a utilização das operações de soma e subtração para ser aplicada. (Governo da Bahia, 2000). 
Sobre o histórico-legislativo pode-se perceber algumas influências internacionais na Lei de Responsabilidade Fiscal Brasileira, segundo Claudiano (2011) dentre elas tem-se: o fundo monetário internacional; a Nova Zelândia através do Fiscal ResponsibilityAct; comunidade econômica Europeia, a partir do Tratado de Maastricht; os estados unidos, cujas as normas de disciplina e controle de gastos do governo central levaram a edição do Budget EnforcementAct, aliado ao principio accountability.

O segmento social possui recursos escassos e grande necessidade de investimento. Dito de outra forma, as receitas não são suficientes para cobrir os gastos e despesas dos órgãos públicos, a fim de satisfazer as necessidades da coletividade, gerando assim um déficit orçamentário na administração pública. Para cobrir esse déficit os gestores públicos acabam por buscar recursos financeiros através de empréstimos isso faz que, com a passagem do tempo, o município contraia dívidas enormes, deixando-as de herança para gestões posteriores, o que gera uma crescente dívida.

Essas são algumas influências que contribuíram para a configuração da Lei de Responsabilidade Fiscal brasileira. No entanto, não foram as únicas, pois como sugere Claudiano (2011), não há um modelo ótimo de como deve se lidar com as finanças públicas.

Em 1995 teve início o programa de Apoio à reestruturação e ao Ajuste Fiscal do Estado, com o Voto 162 do Conselho Monetário Nacional - CMN, segundo Claudiano (2011), tendo como utilidade o refinanciamento de dívidas estaduais e abertura de linhas de credito para ações emergenciais.

A lei $n^{\circ} 9.496$ foi editada em setembro de 1997 e permitiu que a União assumisse a dívida pública mobiliária dos Estados e do Distrito Federal, entre elas as dívidas assumidas pelo voto 162/95, ganhando segundo Claudiano (2011) uma busca pelo desenvolvimento autossustentável.

Em resumo pode-se afirmar que a LRF foi baseada e influenciada por experiências internacionais e foi se adaptando e modificando com o tempo e tem como objetivo principal a regulação das financias públicos, usando para isso, diversos dispositivos e recursos. Para Gerigk e Clemente (2011):

(...) a LRF busca essencialmente o equilíbrio fiscal na gestão pública, mas os limites impostos não consideram as características heterogêneas dos municípios. Percebe-se que diversas pesquisas versam sobre o comportamento das finanças municipais em relação aos limites impostos pela nova legislação fiscal; mas, ainda, não são nítidos os efeitos dessas imposições sobre a administração financeira municipal, principalmente nos municípios menores, que dependem, quase exclusivamente, de transferências constitucionais.

Isso mostra uma limitação da LRF uma vez que a mesma não leva em consideração as especificidades de alguns municípios. Já sobre a aplicabilidade prática, pode-se afirmar que a Lei de Responsabilidade Fiscal contribui de forma consistente para a organização financeira e tributária do Brasil, de modo a tornar transparente e segura as decisões financeiras tomadas pela Administração 
Id on Line Revista Multidisciplinar e de Psicologia

Id on Line Multidisciplinary and Psychology Journal

Pública. No cotidiano pode-se perceber isso, quando a administração não consegue comprovar suas despesas e se abre um processo de investigação e ou são revistas essas despesas.

Por fim, pode-se concluir que a Lei de Responsabilidade Fiscal trouxe importantes contribuições para o ajuste fiscal, potencializando o regime tributário, como também fazendo que os governantes desenvolvessem uma política tributária responsável. A LRF em suas competências tem tornando a administração transparente e democrática, assim a administração deve mostrar o que fazer e de onde vai extrair os seus recursos, garantindo credibilidade ao cidadão, motivando-o a pagar seus tributos democraticamente.

\section{Resultados e Discussões}

Os municípios aqui destacados podem ser caracterizados da seguinte maneira. São municípios em desenvolvimento, que fazem parte do Médio São Francisco, são municípios de pequeno e médio porte, sendo Remanso - BA, o município, como ilustra o gráfico a seguir, menor em número populacional, já Petrolina-PE se destaca com mais de 300 mil habitantes em 2014, segundo dados do IBGE.

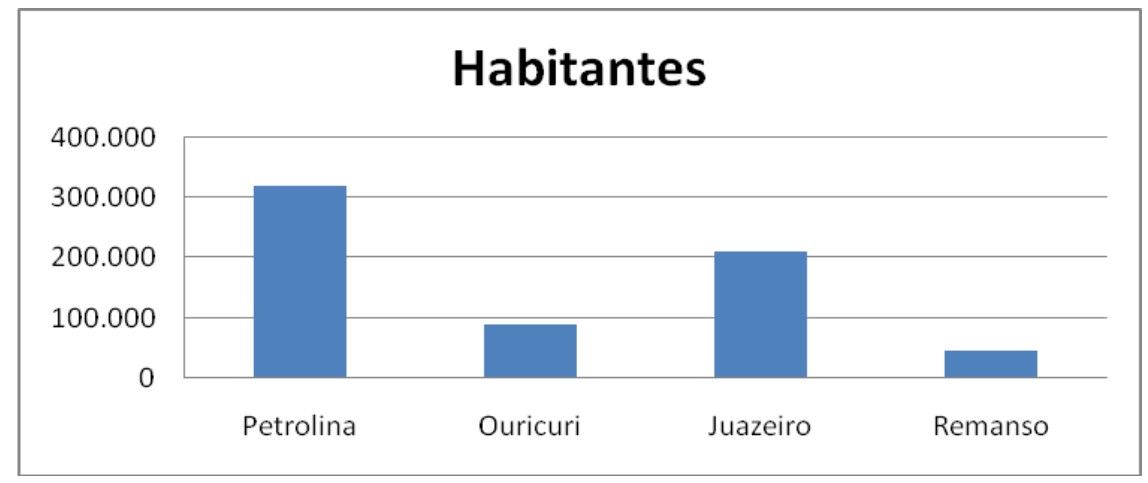

Fonte do Gráfico: IBGE

Um indicador interessante para essa pesquisa é o índice de Desenvolvimento Humano Municipal, uma vez que resultado de um detalhado estudo econômico e social do país, sendo fundamental para subsidiar políticas públicas. O IDHM fornece, ainda, para a população e gestores municipais, ferramentas para o acompanhamento e promoção de melhorias. (BRASIL, 2013). Para se chegar ao IDHM são usadas variáveis com a expectativa de vida ao nascer, escolaridade da população adulta, fluxo escolar da população jovem e a renda per capita. Desse modo pode-se afirmar que de algum modo o IDHM sinaliza o bem-estar social, pois ele reflete os resultados nos investimentos em 
Id on Line Revista Multidisciplinar e de Psicologia

Id on Line Multidisciplinary and Psychology Journal

políticas públicas municipais. A seguir veja o gráfico que explicita o IDHM de 1991, 2010 e 2014, dos municípios do Médio São Francisco.

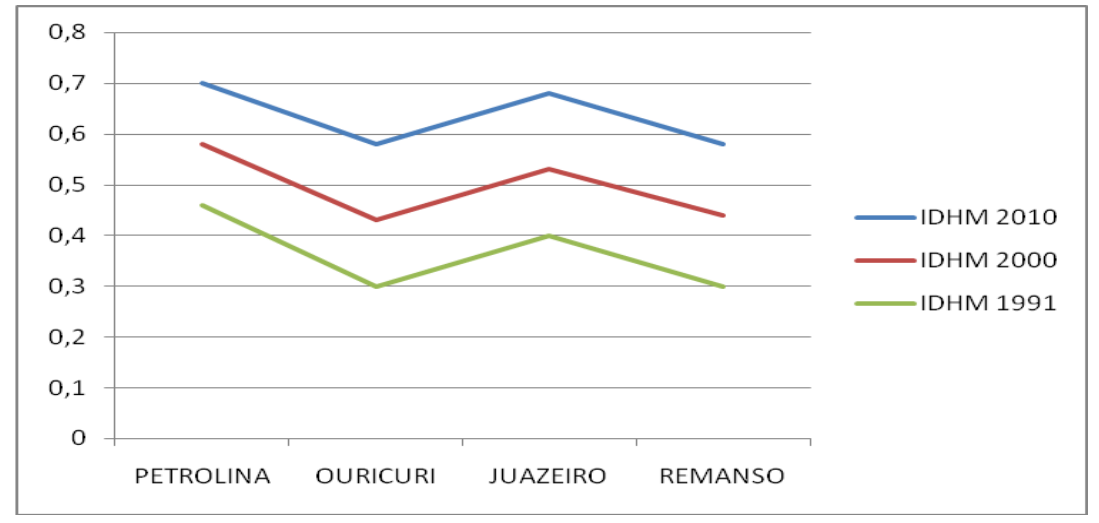

Fonte do Gráfico: IBGE

De um modo geral esses índices sinalizam que o IDHM subiu proporcionalmente em todos os municípios de 1991 até 2010. Percebe-se também que os municípios de médio porte possuem IDHM superior aos de pequeno porte. Diante do exposto, cabe salientar também, o perfil social e aspectos econômicos conforme dados municipais do Boletim do Ministério do Desenvolvimento Social e Combate à Fome.

Segundo dados do Censo Demográfico de 2010 observa-se que em Petrolina o fornecimento de energia elétrica estava presente praticamente em todos os domicílios. A coleta de lixo atendia $88,7 \%$ dos domicílios. Quanto à cobertura da rede de abastecimento de água o acesso estava em $92,0 \%$ dos domicílios particulares permanentes e 73,9\% das residências dispunham de esgotamento sanitário adequado.

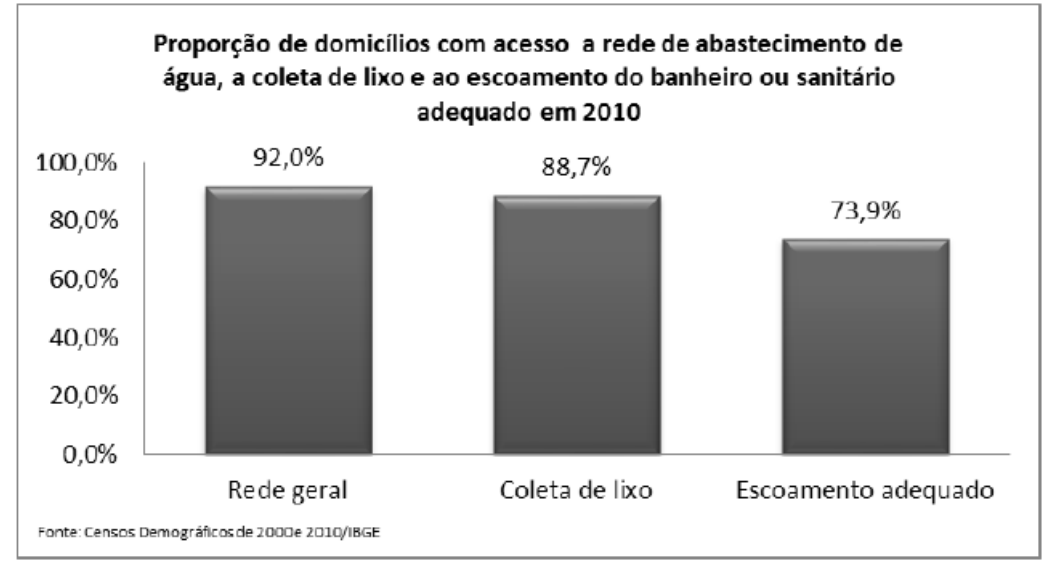

Fonte do Gráfico: IBGE 
Id on Line Revista Multidisciplinar e de Psicologia

Id on Line Multidisciplinary and Psychology Journal

Quanto aos níveis de pobreza, em termos proporcionais, 8,5\% da população está na extrema pobreza, com intensidade maior na área rural (14,9\% da população na extrema pobreza na área rural contra $6,4 \%$ na área urbana).

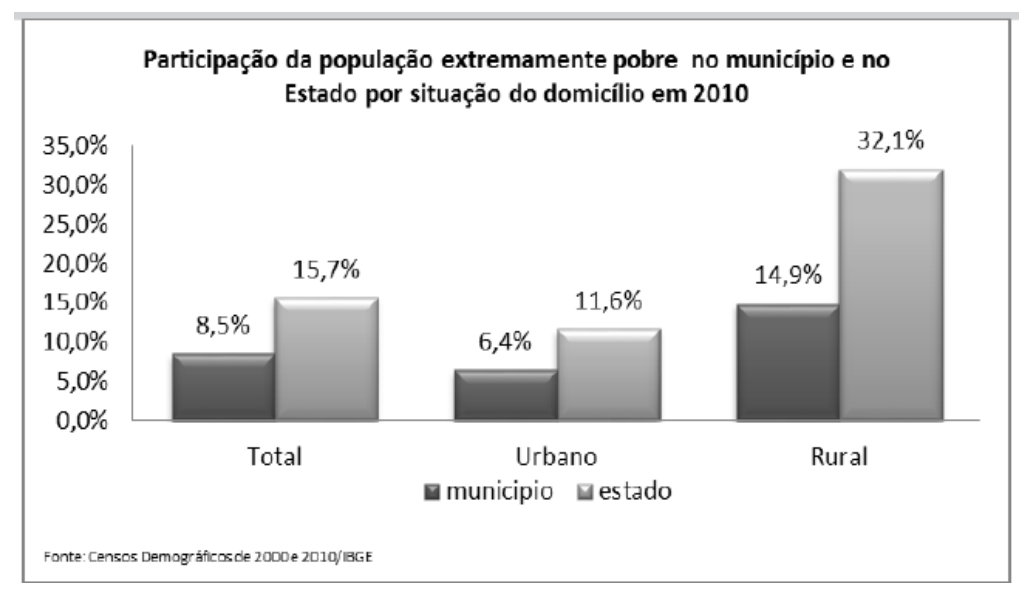

Fonte do Gráfico: IBGE

Em 2010, a taxa de analfabetismo das pessoas de 10 anos ou mais era de 11,1\%. Na área urbana, a taxa era de 8,0\% e na zona rural era de 20,5\%. Entre adolescentes de 10 a 14 anos, a taxa de analfabetismo era de $4,4 \%$.

Entretanto, cabe destacar também no que se refere aos aspectos econômicos que entre 2005 e 2009, segundo o IBGE, o Produto Interno Bruto (PIB) do município cresceu 36,7\%, passando de $\mathrm{R} \$ 1.670,5$ milhões para $\mathrm{R} \$ 2.283,3$ milhões. O crescimento percentual foi inferior ao verificado no Estado que foi de $57,1 \%$. A participação do PIB do município na composição do PIB estadual diminuiu de 3,35\% para 2,91\% no período de 2005 a 2009.

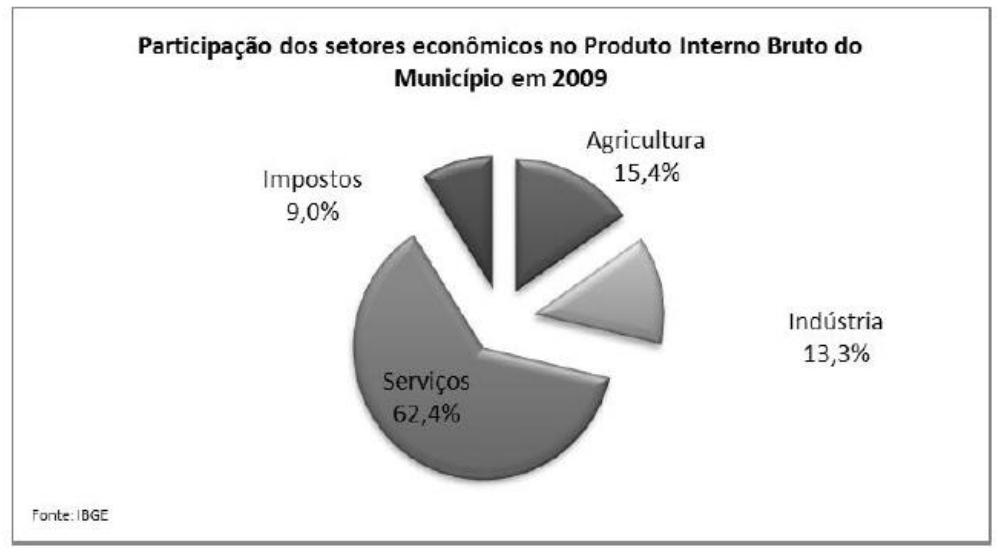

Fonte do Gráfico: IBGE

A estrutura econômica municipal demonstrava participação expressiva do setor de Serviços, o qual responde por $62,4 \%$ do PIB municipal. Cabe destacar o setor secundário ou industrial, cuja 
Id on Line Revista Multidisciplinar e de Psicologia

Id on Line Multidisciplinary and Psychology Journal

participação no PIB era de 13,3\% em 2009 contra 21,5\% em 2005. No mesmo sentido ao verificado no Estado, em que a participação industrial decresceu de 21,5\% em 2005 para 18,9\% em 2009.

A receita orçamentária do município passou de $\mathrm{R} \$ 144,8$ milhões em 2005 para $\mathrm{R} \$ 290,1$ milhões em 2009, o que retrata uma alta de $100,3 \%$ no período ou $18,97 \%$ ao ano. A proporção das receitas próprias, ou seja, geradas a partir das atividades econômicas do município, em relação à receita orçamentária total, passou de 24,21\% em 2005 para 19,58\% em 2009, e quando se analisa todos os municípios juntos do estado, a proporção aumentou de 19,65\% para 19,54\%. A dependência em relação ao Fundo de Participação dos Municípios (FPM) diminuiu no município, passando de 23,15\% da receita orçamentária em 2005 para 18,02\% em 2009. Essa dependência foi inferior àquela registrada para todos os municípios do Estado, que ficou em 26,84\% em 2009.

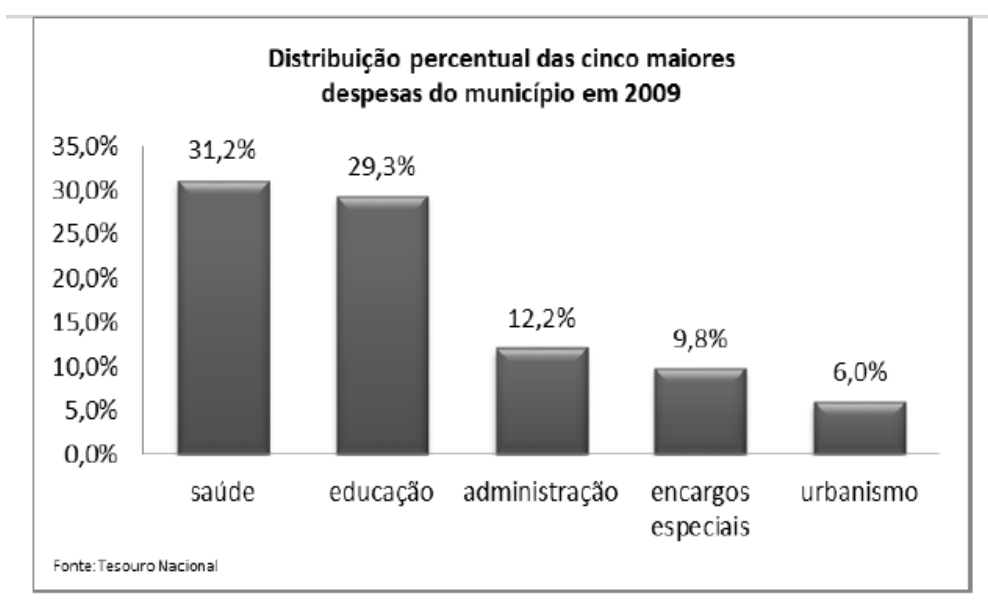

Fonte do Gráfico: IBGE

As despesas com saúde, educação, administração, encargos especiais e urbanismo foram responsáveis por $88,44 \%$ das despesas municipais. Em assistência social, as despesas alcançaram $1,92 \%$ do orçamento total, valor esse inferior à média de todos os municípios do estado, de 4,42\% .

Com relação ao município de Ouricuri- PE, dados do Censo Demográfico de 2010 revelaram o fornecimento de energia elétrica estava presente praticamente em todos os domicílios. A coleta de lixo atendia 45,6\% dos domicílios. Quanto à cobertura da rede de abastecimento de água o acesso estava em 58,3\% dos domicílios particulares permanentes e 61,1\% das residências dispunham de esgotamento sanitário adequado. 
Id on Line Revista Multidisciplinar e de Psicologia

Id on Line Multidisciplinary and Psychology Journal

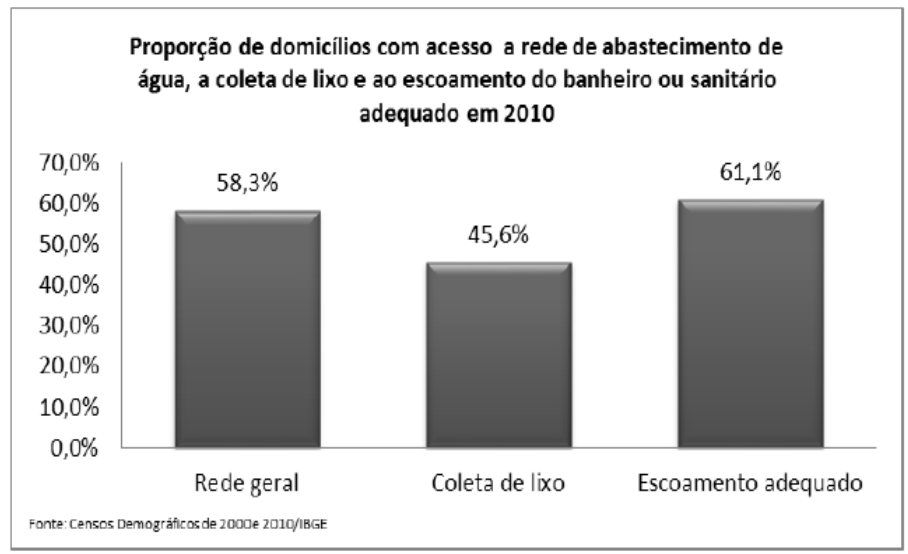

Fonte do Gráfico: IBGE

Quanto aos níveis de pobreza, em termos proporcionais, 30,2\% da população está na extrema pobreza, com intensidade maior na área rural $(43,8 \%$ da população na extrema pobreza na área rural contra $16,9 \%$ na área urbana).

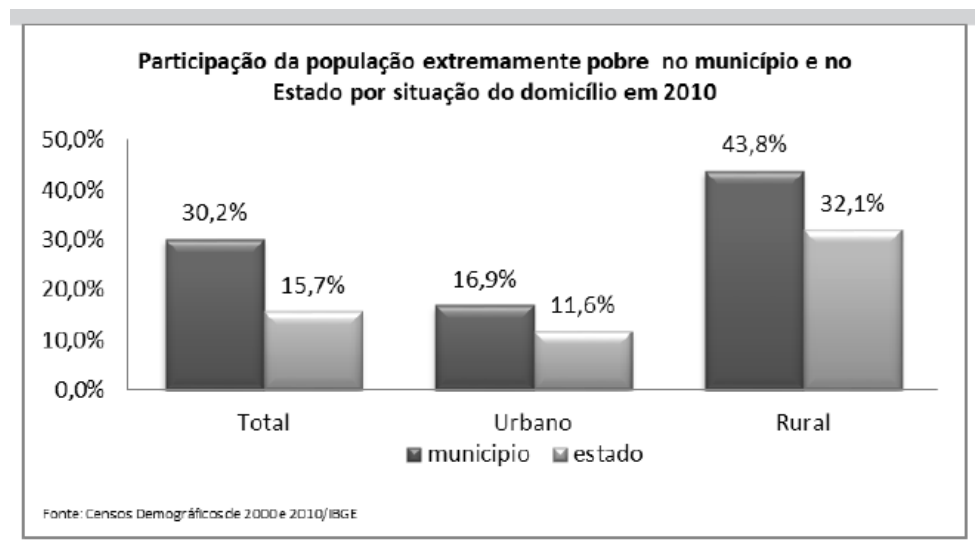

Fonte do Gráfico: IBGE

Em 2010, a taxa de analfabetismo das pessoas de 10 anos ou mais era de 26,9\%. Na área urbana, a taxa era de 18,6\% e na zona rural era de 35,6\%. Entre adolescentes de 10 a 14 anos, a taxa de analfabetismo era de $15,6 \%$.

Entre 2005 e 2009, segundo o IBGE, o Produto Interno Bruto (PIB) do município cresceu $73,5 \%$, passando de $\mathrm{R} \$ 153,5$ milhões para $\mathrm{R} \$ 266,5$ milhões. O crescimento percentual foi superior ao verificado no Estado que foi de 57,1\%. A participação do PIB do município na composição do PIB estadual aumentou de $0,31 \%$ para $0,34 \%$ no período de 2005 a 2009. 
Id on Line Revista Multidisciplinar e de Psicologia

Id on Line Multidisciplinary and Psychology Journal

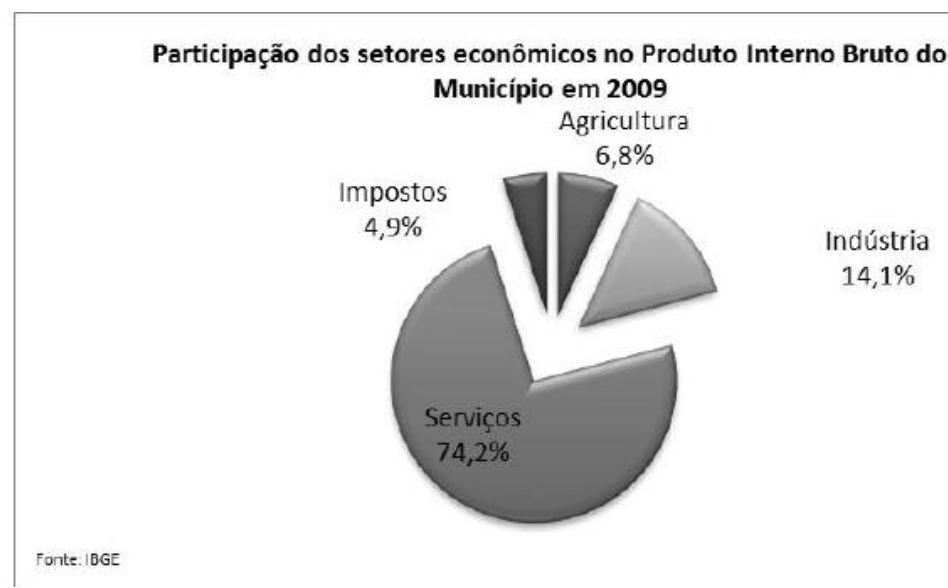

Fonte do Gráfico: IBGE

A estrutura econômica municipal demonstrava participação expressiva do setor de Serviços, o qual responde por 74,2\% do PIB municipal. Cabe destacar o setor secundário ou industrial, cuja participação no PIB era de 14,1\% em 2009 contra 15,0\% em 2005. Em sentido contrário ao verificado no Estado, em que a participação industrial cresceu de 15,0\% em 2005 para 18,9\% em 2009.

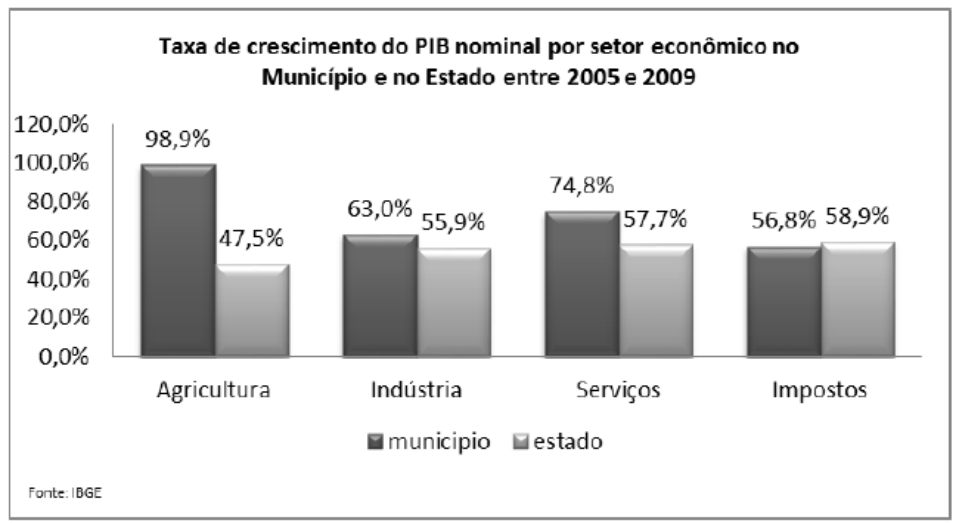

Fonte do Gráfico: IBGE

A receita orçamentária do município passou de $\mathrm{R} \$ 27,7$ milhões em 2005 para $\mathrm{R} \$ 48,2$ milhões em 2009 , o que retrata uma alta de $74,5 \%$ no período ou $14,93 \%$ ao ano. A proporção das receitas próprias, ou seja, geradas a partir das atividades econômicas do município, em relação à receita orçamentária total, passou de 7,12\% em 2005 para 6,51\% em 2009, e quando se analisa todos os municípios juntos do estado, a proporção aumentou de 19,65\% para 19,54\%. A dependência em relação ao Fundo de Participação dos Municípios (FPM) diminuiu no município, passando de 39,60\% da receita orçamentária em 2005 para 38,62\% em 2009. Essa dependência foi superior àquela registrada para todos os municípios do Estado, que ficou em 26,84\% em 2009. 
Id on Line Revista Multidisciplinar e de Psicologia

Id on Line Multidisciplinary and Psychology Journal

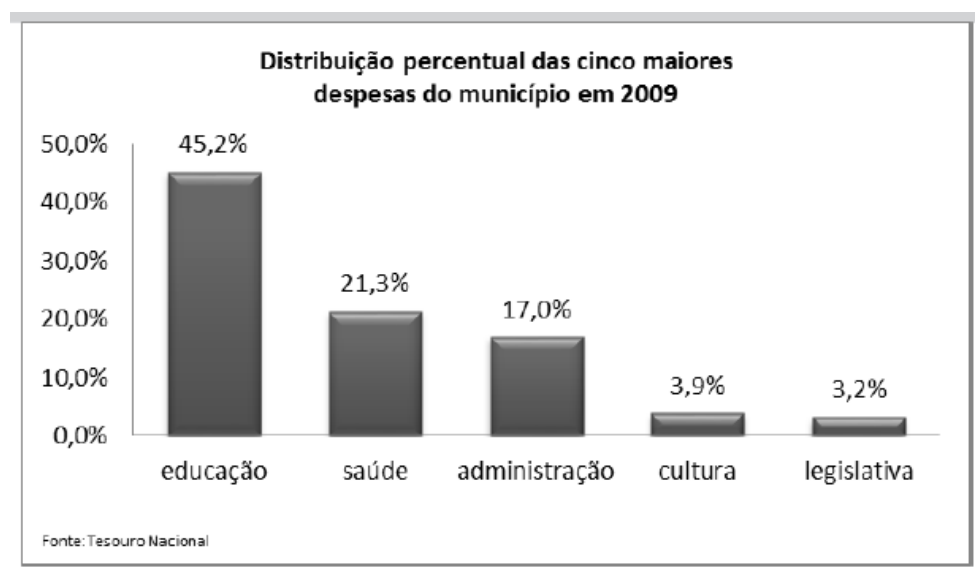

Fonte do Gráfico: IBGE

É notório que as despesas com educação, saúde, administração, cultura e legislativa foram responsáveis por $90,64 \%$ das despesas municipais. Em assistência social, as despesas alcançaram $2,42 \%$ do orçamento total, valor esse inferior à média de todos os municípios do estado, de $4,42 \%$.

Neste sentido, faz-se necessário apresentar também os dados sociais e econômicos dos Municípios baianos: Juazeiro e Remanso.

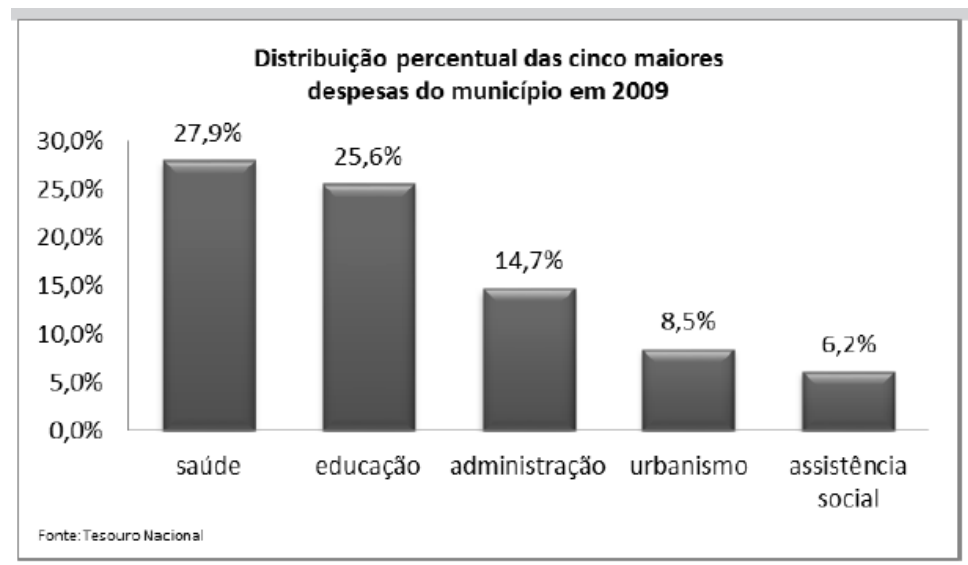

Fonte do Gráfico: Tesouro Nacional

Em Juazeiro-BA de acordo com os dados do Censo Demográfico de 2010 revelaram que o fornecimento de energia elétrica estava presente praticamente em todos os domicílios. A coleta de lixo atendia $83,7 \%$ dos domicílios. Quanto à cobertura da rede de abastecimento de água o acesso estava em 90,8\% dos domicílios particulares permanentes e 65,2\% das residências dispunham de esgotamento sanitário adequado. Quanto aos níveis de pobreza, em termos proporcionais, $10,2 \%$ da população está na extrema pobreza, com intensidade maior na área rural $(17,1 \%$ da população na extrema pobreza na área rural contra 8,6\% na área urbana). 
Id on Line Revista Multidisciplinar e de Psicologia

Id on Line Multidisciplinary and Psychology Journal

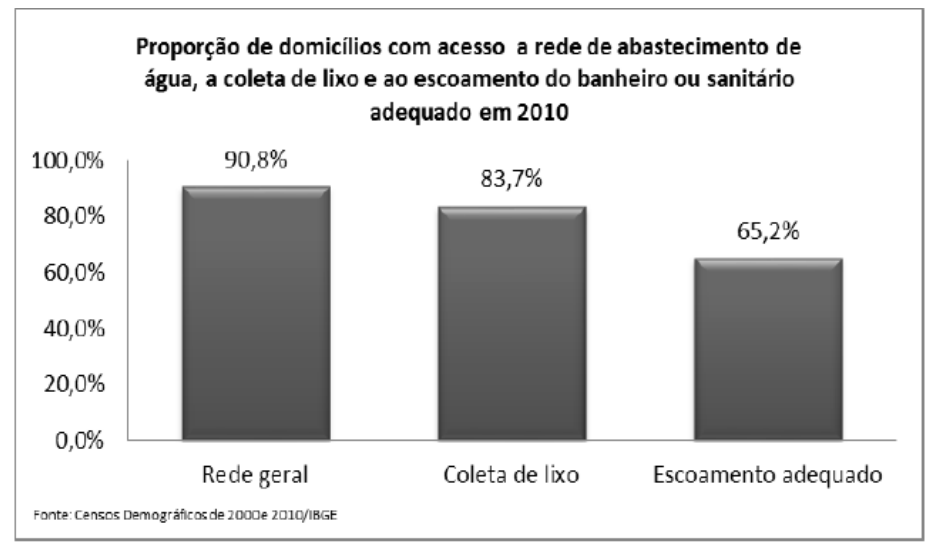

Fonte do Gráfico: IBGE

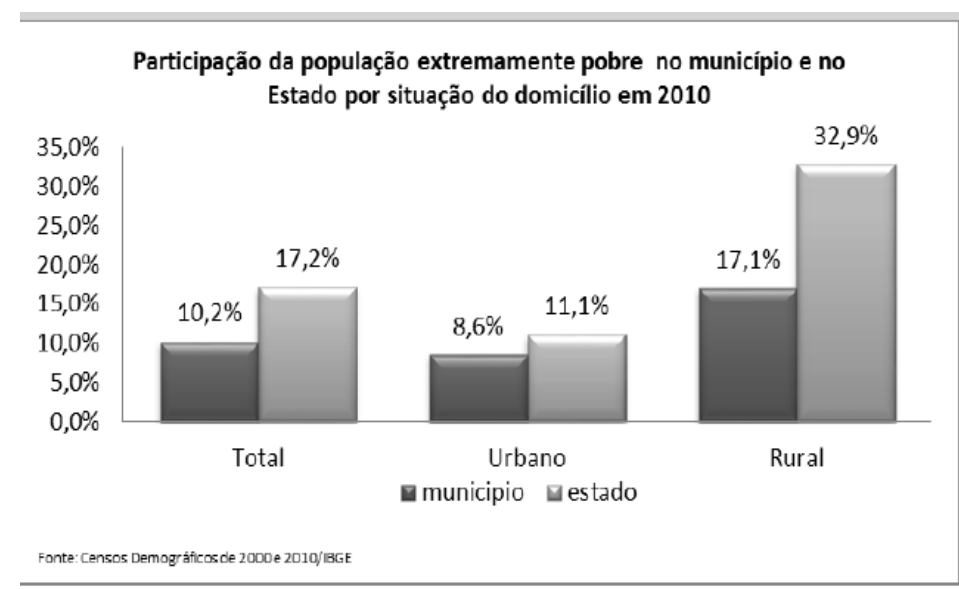

Fonte do Gráfico: IBGE

Em 2010, a taxa de analfabetismo das pessoas de 10 anos ou mais era de 12,5\%. Na área urbana, a taxa era de $10,9 \%$ e na zona rural era de $19,4 \%$. Entre adolescentes de 10 a 14 anos, a taxa de analfabetismo era de $6,0 \%$.

Entre 2005 e 2009, segundo o IBGE, o Produto Interno Bruto (PIB) do município cresceu $53,7 \%$, passando de $\mathrm{R} \$ 1.136,1$ milhões para $\mathrm{R} \$ 1.746,0$ milhões. O crescimento percentual foi superior ao verificado no Estado que foi de 50,8\%. A participação do PIB do município na composição do PIB estadual aumentou de $1,25 \%$ para $1,27 \%$ no período de 2005 a 2009 . A estrutura econômica municipal demonstrava participação expressiva do setor de Serviços, o qual responde por 64,5\% do PIB municipal. Cabe destacar o setor secundário ou industrial, cuja participação no PIB era de 12,9\% em 2009 contra 14,7\% em 2005. Em sentido contrário ao verificado no Estado, em que a participação industrial cresceu de 14,7\% em 2005 para 25,4\% em 2009. 
Id on Line Revista Multidisciplinar e de Psicologia

Id on Line Multidisciplinary and Psychology Journal

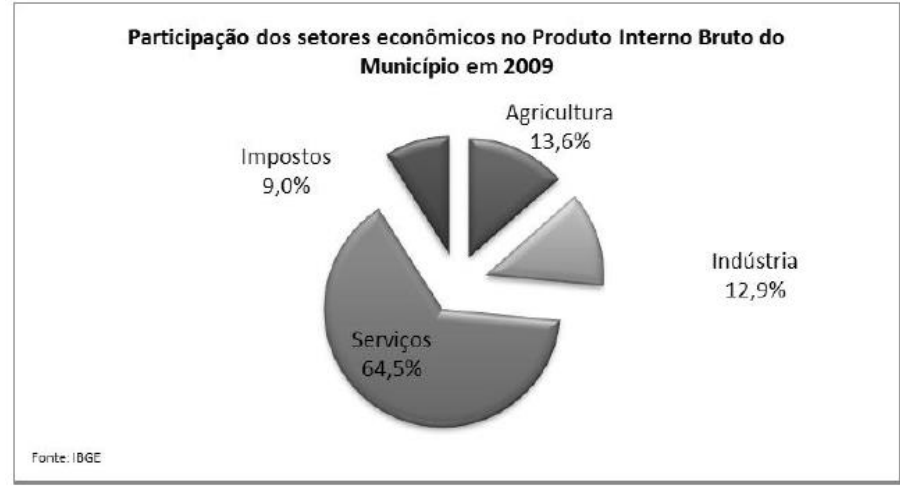

Fonte do Gráfico: IBGE

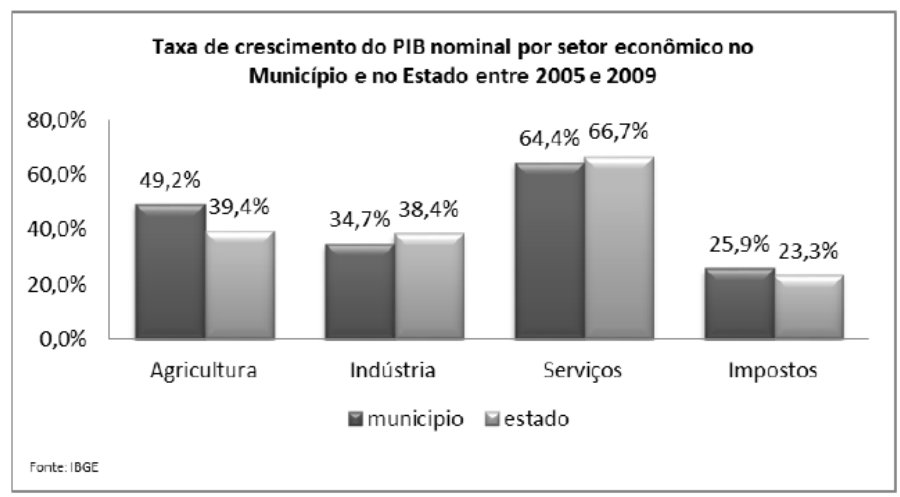

Fonte do Gráfico: IBGE

A receita orçamentária do município passou de R - em 2005 para $\mathrm{R} \$ 233,2$ milhões em 2009, o que retrata uma - de - no período ou - ao ano. A proporção das receitas próprias, ou seja, geradas a partir das atividades econômicas do município, em relação à receita orçamentária total, passou de - em 2005 para 12,00\% em 2009, e quando se analisa todos os municípios juntos do estado, a proporção aumentou de 16,34\% para 16,02\%. A dependência em relação ao Fundo de Participação dos Municípios (FPM) - no município, passando de - da receita orçamentária em 2005 para 20,40\% em 2009. Essa dependência foi inferior àquela registrada para todos os municípios do Estado, que ficou em $28,20 \%$ em 2009.

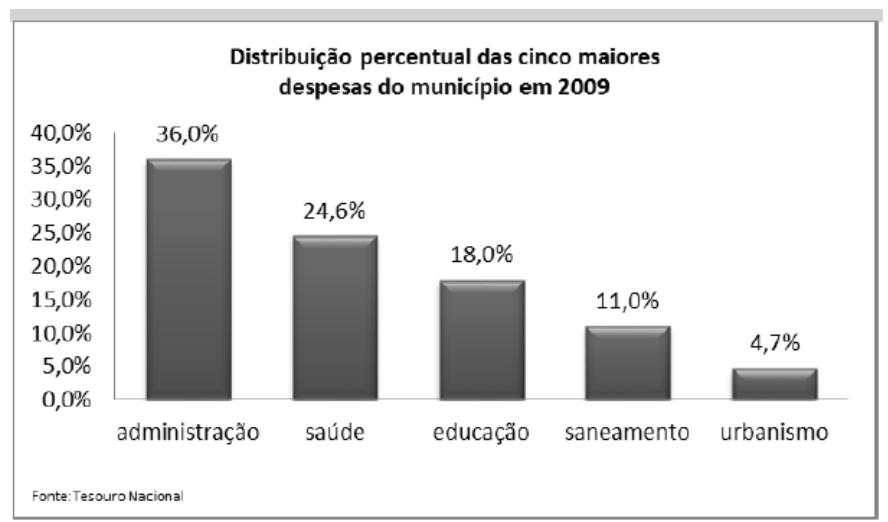

Fonte do Gráfico: IBGE 
Id on Line Revista Multidisciplinar e de Psicologia

Id on Line Multidisciplinary and Psychology Journal

As despesas com administração, saúde, educação, saneamento e urbanismo foram responsáveis por $94,36 \%$ das despesas municipais. Em assistência social, as despesas alcançaram $1,89 \%$ do orçamento total, valor esse inferior à média de todos os municípios do estado, de 2,94\%.

No município de Remanso - BA os dados do Censo Demográfico de 2010 revelaram que o fornecimento de energia elétrica estava presente praticamente em todos os domicílios. A coleta de lixo atendia $61,3 \%$ dos domicílios. Quanto à cobertura da rede de abastecimento de água o acesso estava em 65,1\% dos domicílios particulares permanentes e 50,0\% das residências dispunham de esgotamento sanitário adequado. Quanto aos níveis de pobreza, em termos proporcionais, 27,7\% da população está na extrema pobreza, com intensidade maior na área rural $(47,5 \%$ da população na extrema pobreza na área rural contra 14,6\% na área urbana).

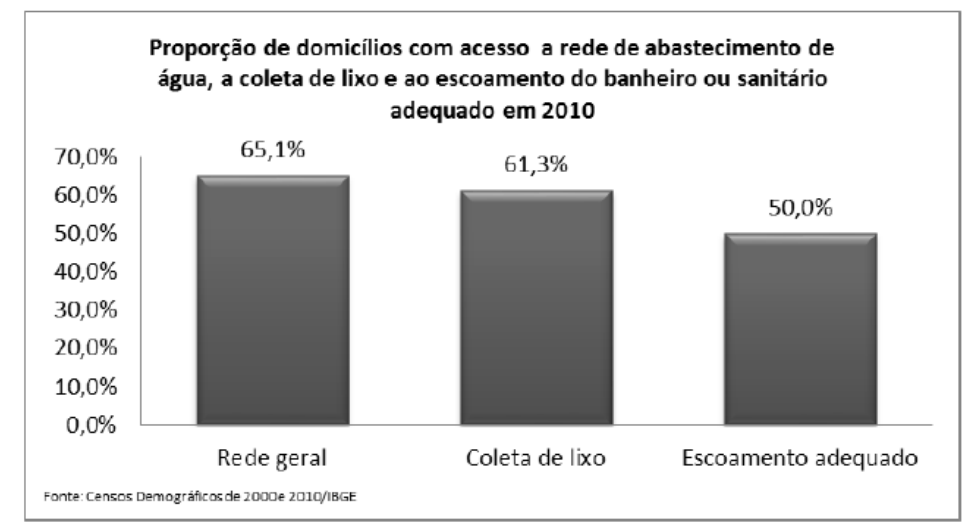

Fonte do Gráfico: IBGE

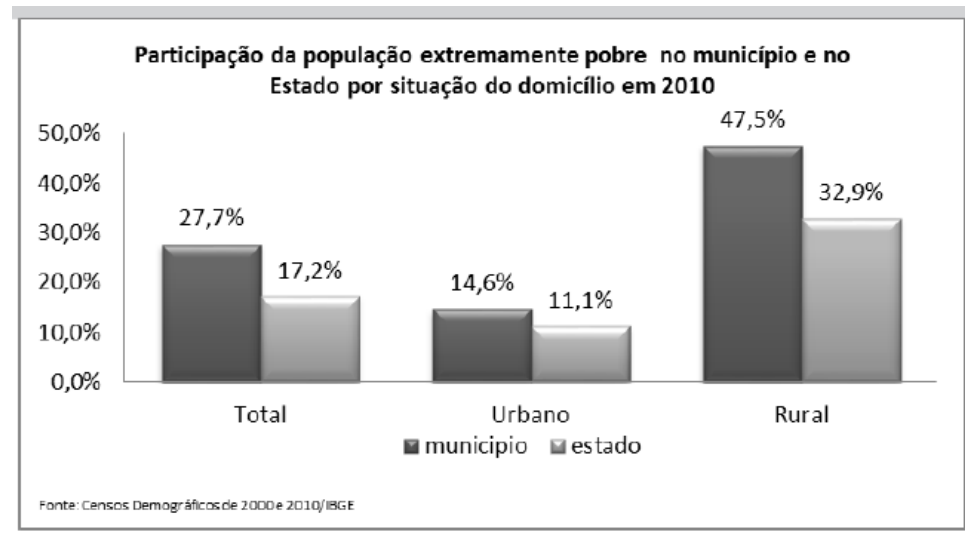

Fonte do Gráfico: IBGE

Em 2010, a taxa de analfabetismo das pessoas de 10 anos ou mais era de 25,5\%. Na área urbana, a taxa era de $17,6 \%$ e na zona rural era de $37,5 \%$. Entre adolescentes de 10 a 14 anos, a taxa de analfabetismo era de $11,5 \%$.

Entre 2005 e 2009, segundo o IBGE, o Produto Interno Bruto (PIB) do município cresceu $50,3 \%$, passando de $\mathrm{R} \$ 103,2$ milhões para $\mathrm{R} \$ 155,1$ milhões. O crescimento percentual foi inferior ao verificado no Estado que foi de 50,8\%. A participação do PIB do município na composição do PIB 
Id on Line Revista Multidisciplinar e de Psicologia

Id on Line Multidisciplinary and Psychology Journal

estadual diminuiu de $0,11 \%$ para $0,11 \%$ no período de 2005 a 2009. A estrutura econômica municipal demonstrava participação expressiva do setor de Serviços, o qual responde por $69,2 \%$ do PIB municipal. Cabe destacar o setor secundário ou industrial, cuja participação no PIB era de 7,9\% em 2009 contra 9,3\% em 2005. No mesmo sentido ao verificado no Estado, em que a participação industrial cresceu de 9,3\% em 2005 para 25,4\% em 2009.

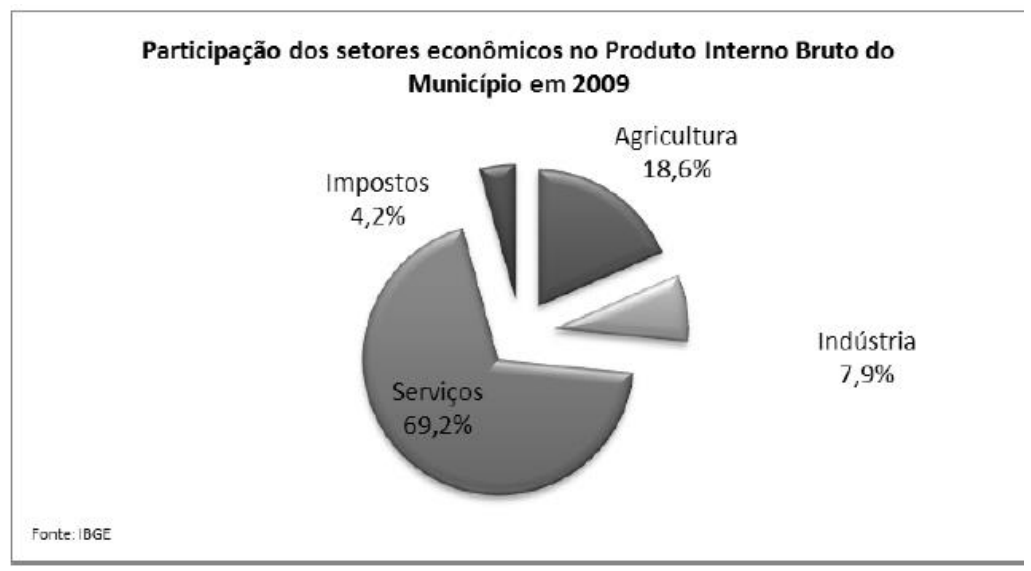

Fonte do Gráfico: IBGE

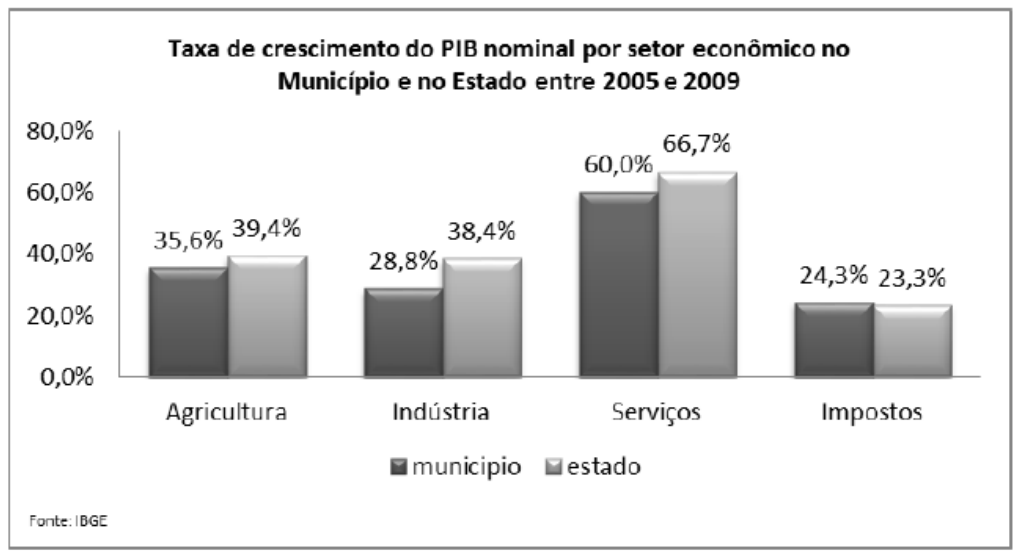

Fonte do Gráfico: IBGE

A receita orçamentária do município passou de $\mathrm{R} \$ 22,4$ milhões em 2005 para $\mathrm{R} \$ 41,0$ milhões em 2009 , o que retrata uma alta de $83,2 \%$ no período ou $16,34 \%$ ao ano a proporção das receitas próprias, ou seja, geradas a partir das atividades econômicas do município, em relação à receita orçamentária total, passou de 3,99\% em 2005 para 13,74\% em 2009, e quando se analisa todos os municípios juntos do estado, a proporção aumentou de 16,34\% para 16,02\%. A dependência em relação ao Fundo de Participação dos Municípios (FPM) diminuiu no município, passando de 38,07\% da receita orçamentária em 2005 para 32,13\% em 2009. Essa dependência foi superior àquela registrada para todos os municípios do Estado, que ficou em 28,20\% em 2009. 


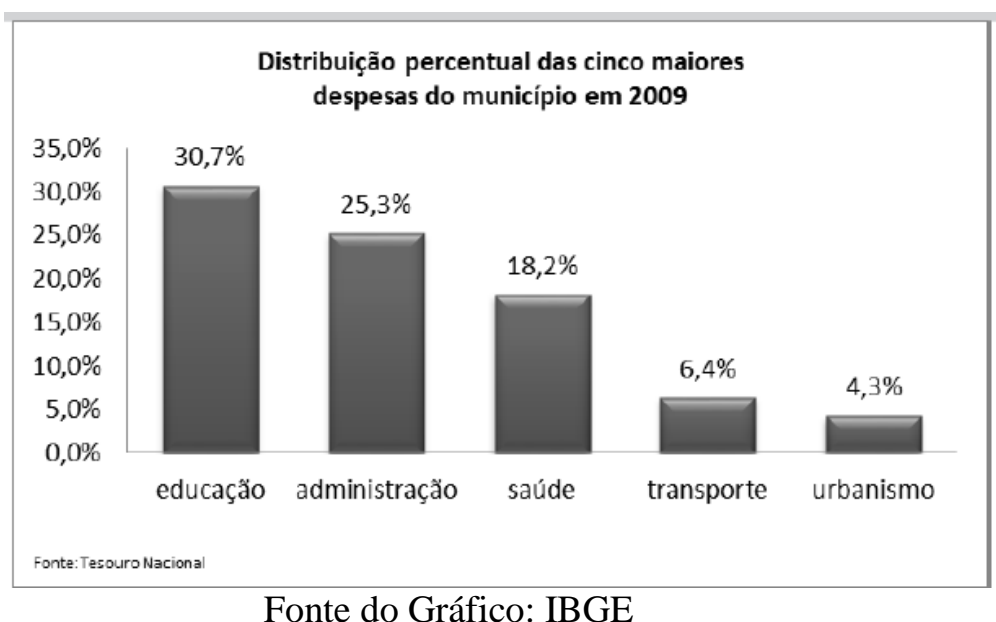

Fonte do Gráfico: IBGE

No município de Remanso - BA, as despesas com educação, administração, saúde, transporte e urbanismo foram responsáveis por $84,88 \%$ das despesas municipais. Em assistência social, as despesas alcançaram $0,03 \%$ do orçamento total, valor esse inferior à média de todos os municípios do estado, de $2,94 \%$.

\section{Conclusão}

Esse projeto foi desenvolvido com o intuito apresentar dados sobre austeridade fiscal e bemestar social e transparência, especificamente, dos municípios de Petrolina, Ouricuri, Juazeiro e Remanso que fazem parte do Sub Médio São Francisco.

Desse modo essa pesquisa em consonância com a Lei de Responsabilidade Fiscal e dados do IBGE, fomenta uma linguagem acessível aos diversos segmentos sociais, uma vez que a leitura e interpretação dos dados divulgados pelos municípios são fáceis de compreensão para o público leigo, o que contribui para formação sobre orçamento público.

É interessante notar que todas as conclusões possíveis com esse trabalho convergem para a presença do "povo" seja como público alvo das ações e execução do Estado seja como parceira no planejamento e/ou fiscal em todas as instancias. Sendo assim podemos concluir que atender as necessidades do "povo" é interesse constante do Estado, e é por isso que se exige o controle da administração, afinal o município tem a responsabilidade de gerir os negócios de interesse da coletividade como afirma a constituição de1988.

É imprescindível analisar e apresentar os dados supracitados, discutindo-os com os diversos segmentos sociais, utilizando-os em reuniões comunitárias, conselhos, conferências, planos municipais, audiências públicas sobre orçamento participativo como: PPA, LDO e LOA, tendo em vista que debates e proposições a partir de dados de uma realidade socioeconômica, contribuem de 
Id on Line Revista Multidisciplinar e de Psicologia

Id on Line Multidisciplinary and Psychology Journal

forma eficaz, combatendo a extrema pobreza com a elaboração e implementação de políticas públicas que visam à inclusão e a melhoria dos serviços sociais.

\section{Referências}

BRASIL. Constituição da República Federativa do Brasil (1988). Disponível em: http://www.planalto.gov.br/ccivil_03/Constituicao/Constituiçao.htm. Acessado em: 11 de maio 2015.

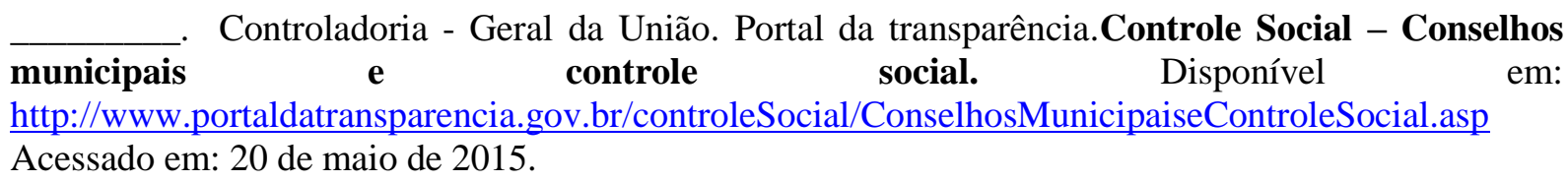

Lei complementar $\mathrm{n}^{\circ} 101$, de 4 de maio de 2000. Estabelece normas de finanças públicas voltadas para a responsabilidade na gestão fiscal e dá outras providências. Disponível em: http://www.planalto.gov.br/ccivil_03/leis/lcp/lcp101.htm. Acessado em: 01 de junho de 2015.

Lei n. 12.919, de 24 de dezembro de 2014. Dispõe sobre as diretrizes para a elaboração e execução da Lei Orçamentária de 2014 e dá outras providências. Disponível em: http://www12.senado.gov.br/orcamento/documentos/ldo/2014/elaboracao/autografos-e-leis/lei/textolei. Acessado em 01 de junho de 2015.

BRASIL. INSTITUTO BRASILEIRO DE GEOGRAFIA E ESTATÍSTICA. IBGE Cidades. Disponível em: http://www.cidades.ibge.gov.br/Acesso em 10 de Outubro de 2015.

CASTRO, J. N. de. Responsabilidade fiscal nos municípios. Belo Horizonte: Ed. Del Rey, 2001. p.33.

CLAUdianO, R. (org.); Ribeiro, R. J. B. Modulo: Administração Pública FPD 6016B. Faculdade Internacional Signorelli. Rio de Janeiro - RJ - Brasil, 2011.

GERIGK, W. Clemente, A. Influência da LRF sobre a Gestão Financeira: Espaço de Manobra dos Municípios Paranaenses Extremamente Pequenos.RAC, Curitiba, v. 15, n. 3, art. 8, pp. 513537, Maio/Jun. 2011.

GIL, A. C.. Métodos e Técnicas de Pesquisa Social. 5. ed. São Paulo: Atlas, 2010.

GONTIJO, C.S.; Araujo, C, F, S. Responsabilidade Fiscal: Adequação Orçamentária e Financeira da Despesa. Monografia. UNB, Brasília, 2006. Disponível em: http://portal2.tcu.gov.br/portal/pls/portal/docs/2054430.PDF. Acessado em 10 de Outubro de 2015.

GOVERNO DA BAHIA. Parâmetros para uma gestão fiscal responsável. 2ª Edição, 2000.

RIBEIRO FILHO, J.F; Controle Gerencial para entidades da Administração Pública. $2^{\circ}$ Prêmio STN de Monografia, 1997.

SALDANHA, C. Introdução à gestão pública. 2. ed. São Paulo, Saraiva, 2006. 
Id on Line Revista Multidisciplinar e de Psicologia

Id on Line Multidisciplinary and Psychology Journal

SENA, L. B., \& Rogers, P. Análise agregada dos municípios mineiros de grande porte quanto a adequação à lei de responsabilidade fiscal (LRF). Anais do Congresso Brasileiro de Custos, João Pessoa, PB, Brasil, 14. 2007.

SERPA, T. S; O principio da transparência na lei de responsabilidade fiscal. Trabalho de Monografia. UFSC, 2005. Disponível em: http://tcc.bu.ufsc.br/Contabeis294257.

<http://aplicacoes.mds.gov.br/sagidata/METRO/metro_ds.php?p_id=236 > Acessado em 05 de junho de 2015.

\section{Como citar este artigo (Formato ABNT)}

MIRANDA, E.S.; NASCIMENTO, D.C. Relação entre Austeridade Fiscal e Bem Social nos Municípios Brasileiros. Id on Line Revista Multidisciplinar e de Psicologia, Julho de 2016, vol.,10 n.30, Supl 1. p. 182201. ISSN 1981-1179.

Recebido: 15/06/2016

Aceito: 20/06/2016 